\title{
Microbial Antagonism at the Root Level Is Involved in the Suppression of Fusarium Wilt by the Combination of Nonpathogenic Fusarium oxysporum Fo47 and Pseudomonas putida WCS358
}

\author{
Ben J. Duijff, Ghislaine Recorbet, Peter A. H. M. Bakker, Joyce E. Loper, and Philippe Lemanceau
}

First, second, and fifth authors: INRA CMSE, Laboratoire de Recherches sur la Flore Pathogène dans le Sol, 17 rue Sully, 21034 Dijon cedex, France; third author: Utrecht University, Department of Plant Ecology and Evolutionary Biology, Section of Plant Pathology, P.O. Box 800843508 TB Utrecht, the Netherlands; and fourth author: Horticultural Crops Research Laboratory, Agricultural Research Service, U.S. Department of Agriculture, Oregon State University, Corvallis. Accepted for publication 3 August 1999.

\begin{abstract}
Duijff, B. J., Recorbet, G., Bakker, P. A. H. M., Loper, J. E., and Lemanceau, P. 1999. Microbial antagonism at the root level is involved in the suppression of Fusarium wilt by the combination of nonpathogenic Fusarium oxysporum Fo47 and Pseudomonas putida WCS358. Phytopathology 89:1073-1079.

Two biological control agents, nonpathogenic Fusarium oxysporum Fo47 and Pseudomonas putida WCS358, were evaluated for suppression of Fusarium wilt of flax grown in nutrient solution and for suppression of the population density and metabolic activity of the causal organism $F$. oxysporum f. sp. lini strain Foln3GUS on root surfaces. Due to the presence of an introduced gusA reporter gene construct in Foln3GUS, the pathogen expressed $\beta$-glucuronidase activity that was related to its carbon metabolism. At a Fo47 to Foln3GUS inoculum ratio of 100:1, both the population density of the pathogen and the $\beta$-glucuronidase activity on and in flax roots were reduced by the nonpathogenic strain, and Fusarium wilt was suppressed. At a Fo47 to Foln3GUS inoculum ratio of 10:1, Fo47 decreased the severity of Fusarium wilt to a smaller extent and it also re-

on flax roots. At a nonpathogenic to pathogenic Fusarium strains ratio of 10:1, the addition of $P$. putida WCS358 further suppressed Fusarium wilt and the density of the pathogen at the root level, whereas a mutant of WCS358 deficient in pseudobactin production had no significant effect. Iron availability to WCS358 on flax roots, assessed by ice-nucleation activity conferred from a transcriptional fusion ( $p v d$-inaZ) of an ice-nucleation reporter gene to an iron-regulated promoter, was sufficiently low to allow pseudobactin production. $P$. putida WCS358 did not reduce the severity of Fusarium wilt of flax when inoculated without Fo47, and it did not improve disease suppression achieved by high inoculum doses of Fo47 (a Fo47 to Foln3GUS ratio of 100:1). Together, these data provide evidence that (i) suppression of Fusarium wilt of flax by Fo47 is related to reductions in the population density and metabolic activity of the pathogen on the root surface; (ii) WCS358 can enhance the biological control activity of Fo47, but this enhancement depends on the population of Fo47 relative to the pathogen; and (iii) pseudobactin contributes to suppression of $\mathrm{Fu}-$ sarium wilt by the combination of Fo47 and WCS358 on roots in which conditions are conducive to pseudobactin production by the bacterium.
\end{abstract} duced $\beta$-glucuronidase activity without reducing the density of Foln3GUS
Natural suppressiveness of some soils to Fusarium wilts has been associated with resident populations of fluorescent pseudomonads and nonpathogenic Fusarium oxysporum $(17,34)$. Some strains of nonpathogenic $F$. oxysporum and fluorescent pseudomonads can suppress Fusarium wilt when applied to roots or seeds of various crop plants $(3,9,10,22)$, but biological control by individual strains can be inconsistent $(35,37)$. Recognizing that natural suppressiveness is not caused by a single microbial population, several workers have tested combinations of nonpathogenic $F$. oxysporum and fluorescent pseudomonads for suppression of Fusarium wilt. Certain strains of fluorescent Pseudomonas spp. can enhance the biological control of Fusarium wilt achieved by nonpathogenic $F$. oxysporum $(4,19,21,23,33)$.

Natural suppressiveness to Fusarium wilts has been related to reduced saprophytic growth of pathogenic $F$. oxysporum (20). The conjoint activities of nonpathogenic $F$. oxysporum and fluorescent Pseudomonas spp. in suppressing Fusarium wilt could be caused by reducing saprophytic growth of the pathogen through carbon and iron competition. This hypothesis was tested previously with a combination of $P$. putida WCS358 and nonpathogenic F. oxy-

Corresponding author: P. Lemanceau; E-mail address: lemanceau@dijon.inra.fr

Publication no. P-1999-0928-01R

(C) 1999 The American Phytopathological Society sporum Fo47, which suppresses Fusarium wilt of carnation more effectively than either antagonistic microorganism inoculated alone (23). Enhanced disease suppression by the microbial combination was related to the production by $P$. putida WCS358 of the siderophore pseudobactin (synonym: pyoverdine) (23). Strain WCS358 enhanced biological control by Fo47, whereas a $\mathrm{Sid}^{-}$mutant of WCS358, deficient in pyoverdine production, did not enhance biocontrol by Fo47 (23). Both purified pyoverdine and nonpathogenic F. oxysporum Fo47 reduced mycelial growth of a pathogenic $F$. oxysporum due to iron and carbon competition, respectively (24).

The aim of the current study was to evaluate at the root level the role of direct antagonism in suppression of Fusarium wilt of flax by Fo47 and WCS358, inoculated individually and in combination. The effect of the biocontrol agents on the density and activity of a gusA-marked derivative of the pathogen was evaluated on roots of flax grown in solution culture. Ice-nucleation activity (INA) expressed by WCS358pvd-inaZ, which contains an ice-nucleation reporter gene $i n a Z$ under the control of an iron-regulated promoter involved in pyoverdine synthesis, was assessed to determine if iron availability on flax roots was sufficiently low for pyoverdine production by $P$. putida.

\section{MATERIALS AND METHODS}

Microorganisms and culture conditions. Nonpathogenic F. oxysporum Fo47 was isolated previously from the Châteaurenard soil 
(France) naturally suppressive to Fusarium wilt; the efficacy of Fo47 in reducing the severity of Fusarium wilt has been demonstrated $(2,13,21)$. Foln 3 is a virulent strain of $F$. oxysporum $\mathrm{f}$. sp. lini. Strain Foln3GUS is a derivative of Foln3 containing a fusion of a promoterless gusA reporter gene to a promoter of $g p d$, the gene encoding glyceraldehyde-3-phosphate dehydrogenase (GPD) from Aspergillus nidulans. GPD catalyzes the second step of glycolysis, and the activity of the gpd promoter relates to the carbon metabolism of the fungus. Therefore, $\beta$-glucuronidase activity conferred from the gusA construct in Foln3GUS indicates the carbon metabolism of the transformed strain $(8,12)$. The pathogenicity of Foln3GUS does not differ from that of the wild-type strain (8). F. oxysporum Fo47 and Foln3GUS are single-spore isolates; they were cryopreserved by freezing conidial suspensions at $-80^{\circ} \mathrm{C}$ in $50 \%$ glycerol. F. oxysporum strains were grown in malt extract liquid medium $\left(10 \mathrm{~g} \mathrm{liter}^{-1}\right)$ at $25^{\circ} \mathrm{C}$. After 7 days of growth, cultures were filtered through glass wool to remove mycelial mats. Microconidia left in the filtrate were pelleted by centrifugation $(5,000 \times g$, $10 \mathrm{~min}$ ) (model GR20-22; Jouan, Saint-Herblain, France) and rinsed three times in $0.01 \mathrm{M} \mathrm{MgSO}_{4}$. The conidial densities of suspensions were determined by direct observation on a haemocytometer and adjusted by dilution.

$P$. putida WCS358 was isolated from the rhizosphere of potato plants (14) and is suppressive to Fusarium wilt $(9,10,19,23)$. Strain JM218 is a siderophore-negative $\left(\mathrm{Sid}^{-}\right)$mutant of WCS358, which was obtained following Tn5 mutagenesis $(5,27)$. Strain WCS358pvdina $Z$ is a derivative of the strain WCS358 containing a transcriptional fusion ( $p v d$-inaZ) of the promoterless inaZ gene, which confers INA, cloned downstream of an 8-kilobase (kb) EcoR1 fragment involved in pyoverdine $(p v d)$ production and uptake by $P$. syringae (25). Cultures of bacterial cells, grown in Luria-Bertani broth medium (30), either supplemented with kanamycin (200 mg liter ${ }^{-1}$ ) for strain JM218 or not supplemented for strain WCS358, were stored at $-80^{\circ} \mathrm{C}$ in $50 \%$ glycerol. Bacterial inoculants were produced on King's medium B agar (KB) plates (16) at $25^{\circ} \mathrm{C}$ for $48 \mathrm{~h}$. Bacteria were scraped from the medium and suspended in $0.01 \mathrm{M}$ $\mathrm{MgSO}_{4}$, pelleted by centrifugation $(5,000 \times g, 10 \mathrm{~min})$, and washed three times. The bacterial densities of the suspensions were measured by direct observation on a haemocytometer and adjusted by dilution.

Treatments and plant growth conditions. Flax seeds (Linum usitatissimum L., cv. Opaline) were sterilized in a $1.25 \%$ solution of $\mathrm{NaOCl}$ for $20 \mathrm{~min}$ and pregerminated for $30 \mathrm{~h}$ on malt agar medium at $25^{\circ} \mathrm{C}$. Two germinated seeds were placed on a wire netting floating at the surface of a nutrient solution $(30 \mathrm{ml})$ in a glass tube $(200 \times 22 \mathrm{~mm})$ and grown for 2 days before microbial inoculation. The nutrient solution consisted of a 1,000-fold dilution of a commercial nutrient stock solution (Hydrokani AO; Hydro Agri, Saint Brice Courcelle, France) to which $\mathrm{Ca}\left(\mathrm{NO}_{3}\right)_{2} \cdot 4 \mathrm{H}_{2} \mathrm{O}(0.65 \mathrm{mM})$ and $2 \mu \mathrm{M} 50 \%$ ferrated form of ethylenediamine-di-(o-hydroxyphenylacetic acid) (EDDHA) (Sigma Chemical Co., St. Louis) were added separately. This nutrient solution was buffered with $100 \mathrm{mM} \mathrm{N}-2$ hydroxyethylpiperazine- $N^{\prime}$-2-ethanesulfonic acid (HEPES) ( $\left.\mathrm{pH} 7\right)$ Sigma Chemical Co.), filter-sterilized, and aerated with filter-sterilized air.

Inoculation was performed by dipping the roots, located on the wire netting, in the appropriate microbial suspension for $1 \mathrm{~h}$. All plants were infested with a conidial suspension of Foln3GUS $\left(10^{3}\right.$ conidia per ml). Control plants were only inoculated with Foln3GUS. Protected plants were also simultaneously inoculated with Fo47, WCS358, or JM218. The biocontrol agents were inoculated, either in combination or separately, together with the pathogen. The density of the bacterial suspensions used for the inoculation was $10^{5}$ cells per ml. To obtain different inoculum ratios of Fo47 to Foln3GUS (10:1 and 100:1), two different densities of Fo47 were used for inoculation $\left(10^{4}\right.$ and $10^{5}$ conidia per $\left.\mathrm{ml}\right)$. Plants were grown in a growth cabinet, previously sterilized with a $12 \%$ solution of $\mathrm{NaOCl}$ on a cycle of 16 -h light $\left(25^{\circ} \mathrm{C}\right)$ and 8 -h dark $\left(23^{\circ} \mathrm{C}\right)$, and harvested
10 days after microbial inoculation. Disease severity was assessed by recording the number of wilted leaves on two plants from each of nine replicates. This way of measuring the disease severity was chosen in order to record early manifestation of the symptoms because the gnotobiotic conditions only allow a short period of plant growth. The results were expressed as the percentage of wilted leaves.

Root colonization by the microorganisms. Root colonization by $P$. putida and $F$. oxysporum was evaluated by counting the number of $\mathrm{CFU}$ from four replicates of two plants each. From each plant, $50 \mathrm{mg}$ of fresh root tissue were placed in a sterile glass tube containing $5 \mathrm{ml}$ of $0.01 \mathrm{M} \mathrm{MgSO}_{4}$ and $1 \mathrm{~g}$ of glass beads $(0.18 \mathrm{~mm}$ in diameter). Tubes were shaken for $30 \mathrm{~s}$ on a vortex mixer (Scientific Industries Inc., Bohemia, NY). A sample (100 $\mu \mathrm{l})$ from each appropriate dilution was plated on KB (14) to evaluate the population size of $P$. putida, and on Komada (18) to evaluate the population size of $F$. oxysporum. Dilutions also were plated on Bacto peptone agar (Difco Laboratories, Detroit) in order to check the gnotobiotic conditions. The CFU were counted after incubation of plates for $48 \mathrm{~h}$ at $27^{\circ} \mathrm{C}$. Colonies of Foln3GUS and Fo47 on the same agar plate were distinguished by the $\beta$-glucuronidase activity of Foln3GUS. Plates were sprayed with a $0.1 \%$ solution of 5-bromo-4-chloro-3-indolyl- $\beta$-glucoronide (X-gluc) (Sigma Chemical Co.) in phosphate buffer $(0.1 \mathrm{M}, \mathrm{pH} 7)$ and incubated for one more day. The blue-stained colonies, indicating $\beta$-glucuronidase activity, were identified as Foln3GUS.

$\beta$-glucuronidase activity of pathogenic $F$. oxysporum Foln3GUS. The $\beta$-glucuronidase activity of $F$. oxysporum Foln3GUS was measured on root extracts using a fluorimetric assay (14). Per treatment, four replicates, each consisting of the whole root system from two plants, were frozen in liquid nitrogen, ground with a pestle in a chilled mortar, and diluted 10-fold (wt/vol) in an extraction buffer $(0.1 \mathrm{M}$ phosphate buffer, $\mathrm{pH} 6.8 ; 0.5 \mathrm{mM} \beta$-mercaptoethanol; $0.5 \mathrm{mM}$ EDTA, and $171 \mathrm{mM} \mathrm{NaCl}$ ). The root extracts were homogenized ( $2 \mathrm{~min}$ ) with a high-speed homogenizer (Ultra-turax T8; IKA, Staufen, Germany), centrifuged $(5,000 \times g, 10 \mathrm{~min})$, and the supernatants stored at $-80^{\circ} \mathrm{C}$.

Extraction buffer $(450 \mu \mathrm{l})$, supplemented with $0.44 \mathrm{mg}$ of 4methylumbelliferyl glucuronide (MUG) per ml (Sigma Chemical Co.), was added to $50 \mu \mathrm{l}$ of each root extract. After $90 \mathrm{~min}$ of incubation at $37^{\circ} \mathrm{C}$ in the dark, $200 \mu \mathrm{l}$ was removed and the reaction was stopped by adding $1.8 \mathrm{ml}$ of $0.2 \mathrm{M} \mathrm{Na}_{2} \mathrm{CO}_{3}$. Fluorescence of the samples, resulting from the catalysis of MUG to 7-hydroxy-4-methylcoumarin (MU), was measured with a fluorescence spectrophotometer (model SFM 25; Kontron, Montigny Le Bretonneux, France) at $455 \mathrm{~nm}$ after excitation at a wavelength of $365 \mathrm{~nm}$. MU concentrations were normalized for the density of Foln3GUS and results were expressed as micromolar MU per log (CFU). For each replicate, results are the mean of three assays.

Expression of an iron-regulated promoter by WCS358. INA of WCS358pvd-inaZ was assessed to determine whether the conditions on flax roots were favorable to the expression of pyoverdine biosynthesis and uptake genes by $P$. putida WCS358. The pvd-inaZ construct (25) consisted of an 8-kb EcoRI fragment containing pyoverdine biosynthesis and uptake genes from $P$. syringae cloned $5^{\prime}$ to a promoterless ice-nucleation gene (inaZ) in pVSP61, a derivative of plasmid pVS1. pVS1 is stably maintained at six to eight copies per cell in Pseudomonas spp. (15). pvd-inaZ was introduced into WCS358 by conjugation with an Escherichia coli donor strain, as described previously (25).

INA expressed by WCS358pvd-inaZ on flax roots was measured from four replicates, each comprised of two root systems inoculated with either WCS358pvd-inaZ or WCS358. The whole root systems (about $150 \mathrm{mg}$ fresh weight) were shaken with a vortex mixer (Scientific Industries Inc.) in $5 \mathrm{ml}$ of $0.01 \mathrm{M}$ $\mathrm{MgSO}_{4}$ with $0.5 \mathrm{~g}$ of glass beads $(0.18 \mathrm{~mm}$ in diameter) for $30 \mathrm{~s}$. The number of ice nuclei in the resulting suspensions was estimated by the droplet freezing assay (25). Bacterial population 
densities were determined by enumerating CFU as described before. INA of the samples was expressed as log (ice nuclei per cell) (26).

To ensure that the $p v d$-inaZ fusion did not alter pyoverdine production, pyoverdine concentrations in cultures of WCS358pvd-inaZ and WCS358 were compared. The strains were grown in the previously described nutrient solution supplemented with $\operatorname{EDDHA}(2 \mu \mathrm{M}$, chelated with iron at 0,50 , or $100 \%)$, sucrose $(1 \%)$, casamino acids (1\%), and HEPES buffer (100 mM, pH 7). Each experimental treatment was replicated in three different Erlenmeyer flasks. After incubation for $24 \mathrm{~h}$ at $25^{\circ} \mathrm{C}$, cell densities were assessed by measuring the absorbance of the suspensions at $600 \mathrm{~nm}$. Pyoverdine concentration was evaluated by measuring the absorbance of the supernatant at $400 \mathrm{~nm}$, after centrifugation and adjustment of the $\mathrm{pH}$ to 7 , according to the method described by Meyer and Abdallah (29). Absorbance measurements were performed three times for each flask. Pyoverdine concentration was normalized for the density of bacterial cells, and results were expressed as absorbance $400 \mathrm{~nm} /$ absorbance $600 \mathrm{~nm}$.

In a culture medium, the relationship of pyoverdine production to INA expressed by WCS358pvd-inaZ was determined. WCS358pvd-inaZ was grown for $48 \mathrm{~h}$ at $25^{\circ} \mathrm{C}$ with shaking $(200 \mathrm{rpm})$ in RSM, a medium designed to approximate the nutritional composition of the rhizosphere (6). RSM was amended with various concentrations of ferric citrate $\left(10^{-4}\right.$ to $\left.10^{-6} \mathrm{M}\right)$ to increase iron availability. WCS358 and WCS358pvd-inaZ cultured in RSM containing $>10^{-4.3} \mathrm{M}$ ferric citrate produced a noncharacterized pigment that absorbed at $400 \mathrm{~nm}$, the wavelength commonly used to detect pyoverdines in culture supernatants. Therefore, concentrations of pyoverdine produced by WCS358pvd-inaZ in culture media varying in iron content were determined by high-performance liquid chromatography (HPLC) (model 2690; Waters Corporation, Milford, MA), using conditions similar to those described by Nowak-Thompson and Gould (31). Ferric citrate was added to culture supernatants to a final concentration of $10^{-3} \mathrm{M}$, and the mixture was incubated for $60 \mathrm{~min}$. Solids were removed by centrifugation, and $100 \mu \mathrm{l}$ of the supernatant was submitted to HPLC analysis. The column was a Nova-Pak C18 radial compression cartridge $(2.5 \times 10 \mathrm{~cm}, 6 \mu \mathrm{m}$ particle size) (Waters Corporation) eluted with $90 \% 20 \mathrm{mM} \mathrm{NH}_{4} \mathrm{HCO}_{3} /$ $10 \% \mathrm{MeOH}, \mathrm{pH} 6.5$, at a flow rate of $1.5 \mathrm{ml} \mathrm{min}^{-1}$. Several peaks that absorbed at $400 \mathrm{~nm}$ were detected following HPLC analysis of culture supernatants of WCS358, and such peaks typically represent multiple pyoverdines or breakdown products of pyoverdines that are commonly detected in cultures of Pseudomonas spp. (1). Therefore, we used the following procedure to estimate the pyoverdine concentration in cultures of WCS358 varying in iron content. Pyoverdine concentrations in cultures grown in RSM containing $10^{-6} \mathrm{M}$ ferric citrate (an iron concentration in which the interfering purple compound was not detected) were estimated from the absorbance of crude supernatants, using the published extinction coefficient of $1.9 \times 10^{-4} \mathrm{~mol}^{-1} \mathrm{~cm}^{-1}$ (1). A ratio relating absorbance of the crude supernatant to the area under the major HPLC peak absorbing at $400 \mathrm{~nm}$ was determined for cultures grown in RSM containing $10^{-6} \mathrm{M}$ ferric citrate. The retention time of this peak $(10.5 \pm 0.3 \mathrm{~min})$ corresponded to the major peak observed from HPLC analysis of a sample of authentic pyoverdine isolated from WCS358. Pyoverdine concentrations present in supernatants of cultures grown in media with varying ferric citrate concentrations were calculated as the product of that ratio and the area under the peak with a retention time of $10.5 \pm 0.3 \mathrm{~min}$ from each culture.

Statistical analysis. Populations sizes were logarithmically transformed before analysis. The percentages of wilted leaves, indicating the disease severity, were submitted to angular transformation before analysis. Nontransformed and transformed values were submitted to analysis of variance and then Fisher's least significant difference test. All experiments have been duplicated, and the results shown represent one representative experiment.

\section{RESULTS}

Population densities of antagonistic microorganisms. At Fo47 to Foln3GUS inoculum ratios of 10:1 and 100:1, the densities of Fo47 10 days after inoculation were $4.9 \times 10^{6}$ and $1.3 \times 10^{7} \mathrm{CFU}$ per $g$ of fresh root, respectively. These population sizes were significantly different, indicating that differences in inoculum dose influenced populations established by Fo47 on flax roots for at least 10 days. The presence of $P$. putida WCS358 or JM218 did
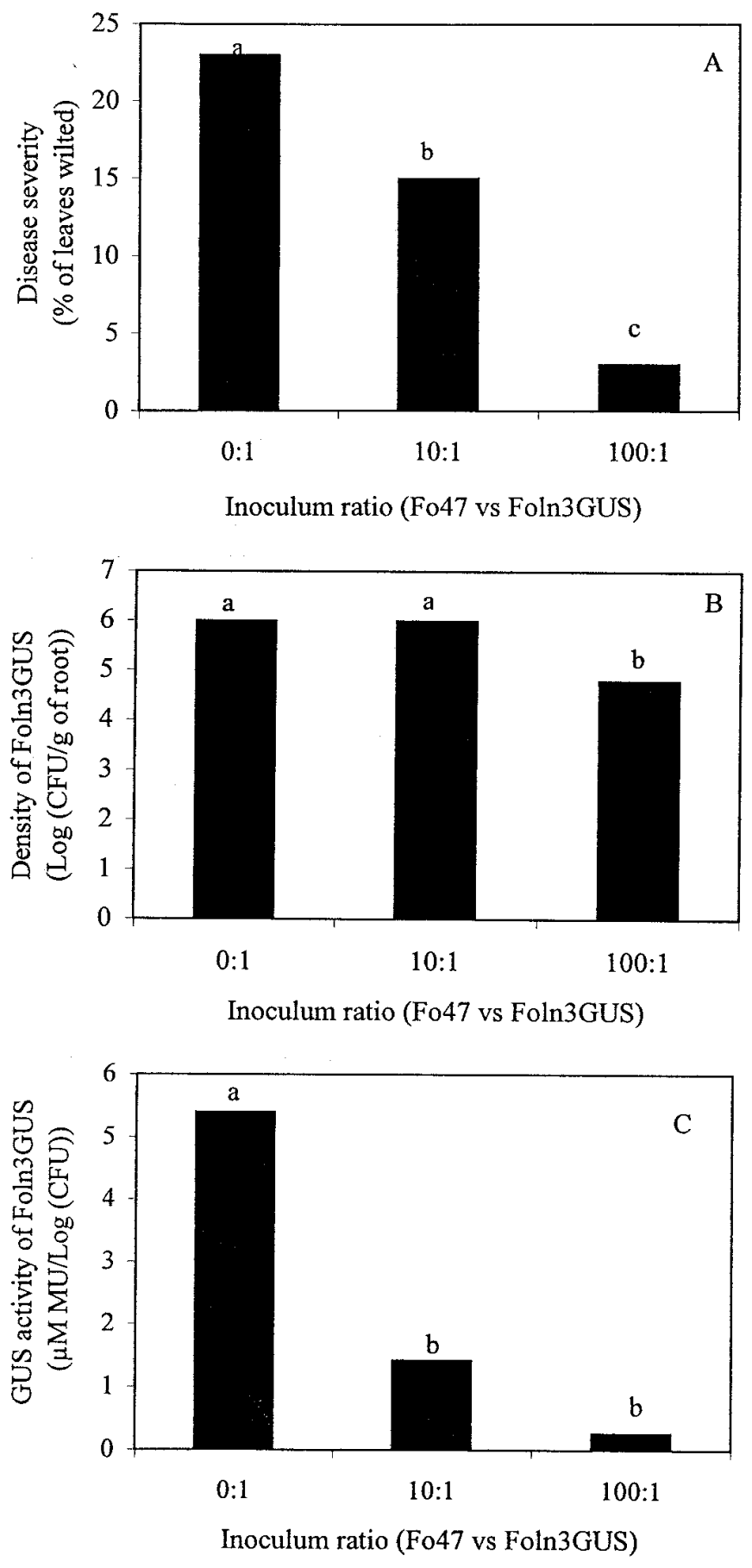

Fig. 1. Effect of inoculum ratios of nonpathogenic Fusarium oxysporum Fo47 to pathogenic $F$. oxysporum Foln3GUS on A, Fusarium wilt severity (percent wilted leaves); $\mathbf{B}$, population size (log [CFU/g of root]); and $\mathbf{C}, \beta$-glucuronidase activity ( $\mu \mathrm{M}$ MU/log [CFU]) of Foln3GUS. Means designated with the same letter are not significantly different $(P \leq 0.05)$ according to Fisher's least significant difference test. Statistical analyses were performed on transformed values both for population size and disease severity. 
not significantly modify population densities of Fo47 on flax roots $(P \leq 0.05)$ (data not shown).

The influence of pyoverdine production on the population densities of $P$. putida on flax roots was assessed by comparing the densities of the wild-type strain WCS358 with those of mutant JM218. At 10 days after their inoculation, the densities of the bacterial strains WCS358 and JM218 in the absence of the nonpathogenic Fo47 $\left(8.9 \times 10^{8}\right.$ and $1.7 \times 10^{9} \mathrm{CFU}$ per $\mathrm{g}$ of fresh root, respectively) were not significantly different $(P \leq 0.05)$. The population sizes of WCS358 and mutant JM218 were not significantly different when inoculated in the presence and in the absence of Fo47 (data not shown).

Effect of nonpathogenic $F$. oxysporum and $P$. putida strains on the severity of Fusarium wilt. Nonpathogenic $F$. oxysporum Fo47 reduced significantly the severity of Fusarium wilt of flax (Fig. 1). There was an improvement in disease suppression achieved by Fo47 when the Fo47 to Foln3GUS inoculum ratio increased from 10:1 to 100:1. To determine the involvement of pyoverdine production in the suppression of Fusarium wilt, bacterial strains WCS358 and JM218 were compared for their ability to suppress Fusarium wilt in the absence or presence of nonpathogenic $F$. oxysporum Fo47. Neither of the bacterial strains inoculated simultaneously with the pathogen (Fo47 to Foln3GUS inoculum ratio equal to $0: 1$ ) significantly reduced disease severity (Fig. 2). At the Fo47 to Foln3GUS inoculum ratio of 10:1, the efficiency of the biocontrol achieved by Fo47 was significantly improved by the addition of the bacterial strain WCS358, and the severity of Fusarium wilt was $41.3 \%$ lower in the presence of Fo47 + WCS358 than in the presence of Fo47 alone. An increase in disease suppression did not occur when Fo47 was coinoculated with JM218 (Fig. 2). At the highest inoculum ratio of Fo47 tested (100:1), coinoculation with WCS358 or JM218 did not improve the efficiency of control by Fo47, and coinoculation with JM218 even significantly increased the disease severity when compared with Fo47 alone. Nevertheless, the disease severity of the plants inoculated with the combination of Fo47 and the bacterial strains remained significantly lower than that of the infested control.

Effect of nonpathogenic $F$. oxysporum and $P$. putida strains on the population density of strain Foln3GUS. Nonpathogenic F. oxysporum Fo47 reduced significantly the densities of Foln3GUS only at the highest inoculum ratio of Fo47 to Foln3GUS (100:1) (Fig. 1). To determine the influence of pyoverdine production on

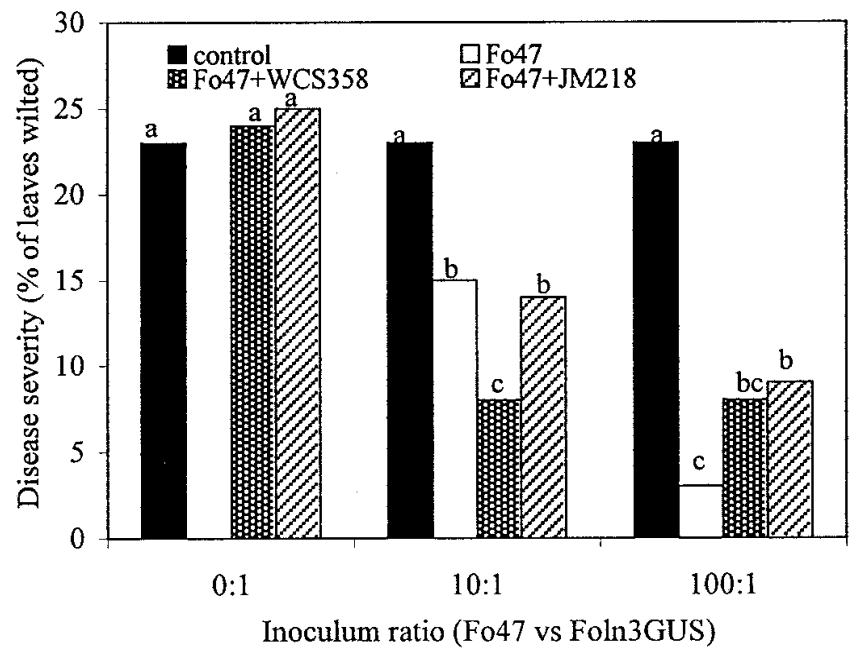

Fig. 2. Effects of Pseudomonas putida WCS358 and the $\mathrm{Sid}^{-}$mutant JM218 on Fusarium wilt severity for different inoculum ratios of nonpathogenic $\mathrm{Fu}$ sarium oxysporum Fo47 to pathogenic F. oxysporum Foln3GUS. For the same Fo47 to Foln3GUS inoculum ratio, means designated with the same letter are not significantly different $(P \leq 0.05)$ according to Fisher's least significant difference test. Statistical analyses were performed on transformed values. the density of the pathogen, the effects of the strains WCS358 and JM218 on this density was compared in the absence or presence of nonpathogenic $F$. oxysporum Fo47. None of the bacterial strains inoculated simultaneously with the pathogen reduced significantly the pathogen density as compared with the control (Fo47 to Foln3GUS inoculum ratio equal to 0:1) (Fig. 3). At the Fo47 to Foln3GUS inoculum ratio of 10:1, the combination of Fo47 and WCS358 reduced significantly the density of Foln3GUS: the population density of Foln3GUS on flax roots was 0.7 log lower in the presence of Fo47 + WCS358 than in the presence of Fo47 alone. In contrast, decrease in the density of the pathogen did not occur when Fo47 was coinoculated with JM218 (Fig. 3). At the highest inoculum ratio (100:1), the addition of WCS358 or JM218 did not further decrease the density of the pathogen below that caused by Fo47 alone.

Effect of nonpathogenic $\boldsymbol{F}$. oxysporum and $\boldsymbol{P}$. putida strains on the $\beta$-glucuronidase activity of Foln3GUS. Nonpathogenic $F$. oxysporum Fo47 reduced significantly the $\beta$-glucuronidase activity associated with flax roots colonized by Foln3GUS (Fig. 1). In addition, $\beta$-glucuronidase activity was further reduced as the inoculum density of the nonpathogenic Fo47 increased from $10^{4}$ to $10^{5}$ conidia per $\mathrm{ml}$, although nonsignificantly. The addition of either WCS358 or JM218 did not significantly modify the effect of Fo47 on $\beta$-glucuronidase activity (Fig. 4).

Transcription of an iron-regulated promoter by $\boldsymbol{P}$. putida in culture and at the root level. Strains WCS358 and WCS358pvdinaZ produced equivalent concentrations of pyoverdine in culture. Furthermore, the pyoverdine synthesis by both strains was reduced with the same magnitude when the iron concentration in the medium was increased (absorbance $400 \mathrm{~nm} /$ absorbance $600 \mathrm{~nm}=1.5$, 1.2, and 1.1 for 0-, 50- and 100\%-ferrated EDDHA, respectively). Therefore, the $p v d$-ina $Z$ construct had no detectable influence on pyoverdine production by WCS358 in culture.

INA and pyoverdine production by WCS358pvd-inaZ decreased in a parallel fashion as the concentration of ferric citrate in RSM increased (Fig. 5). In cultures of WCS358pvd-inaZ grown in RSM amended with ferric citrate concentrations of $5 \times 10^{-5} \mathrm{M}$ or greater, INA was detected, whereas pyoverdine concentrations were below detectable levels. INA was related to pyoverdine production by WCS358pvd-inaZ grown in culture over the full range of iron concentrations in which both phenotypes could be detected. On roots of 12-day-old flax plants grown in the presence of $2 \mu \mathrm{M} 50 \%$

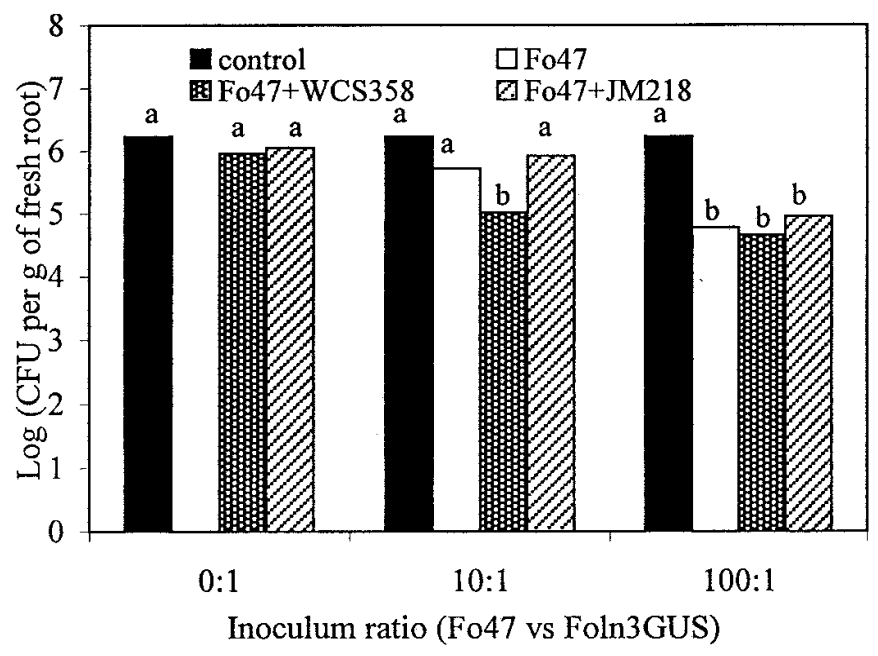

Fig. 3. Effects of Pseudomonas putida WCS358 and the $\mathrm{Sid}^{-}$mutant JM218 on the density of Foln3GUS for different inoculum ratios of nonpathogenic Fusarium oxysporum Fo47 to pathogenic F. oxysporum Foln3GUS. For the same Fo47 to Foln3GUS inoculum ratio, means designated with the same letter are not significantly different $(P \leq 0.05)$ according to Fisher's least significant difference test. Statistical analyses were performed on transformed values. 
ferrated EDDHA, WCS358pvd-inaZ expressed an INA of $-2.3 \log$ (ice nuclei per cell), whereas WCS358 expressed no INA. INA expressed by WCS358pvd-inaZ indicated that iron levels on flax roots were sufficiently low for transcription of inaZ from an ironregulated promoter.

\section{DISCUSSION}

This study confirms previous reports of the ability of nonpathogenic F. oxysporum Fo47 to suppress Fusarium wilts and that the combination of $F$. oxysporum Fo47 and $P$. putida WCS358 increases disease suppression above that provided by either antagonist alone $(3,19,23)$. These data also provide further evidence that nonpathogenic $F$. oxysporum Fo47 and $P$. putida WCS358 decrease population size and activity of pathogenic $F$. oxysporum on roots, that this decrease contributes to disease suppression, and that pyoverdine production is involved in the antagonism of pathogenic $F$. oxysporum by $P$. putida.

As previously described $(3,23)$, Fusarium wilt was suppressed more efficiently when the ratio of nonpathogenic $F$. oxysporum to pathogenic $F$. oxysporum was increased. This disease suppression was shown to be related to the decreased metabolic activity of the pathogen Foln3GUS on and in roots, as assessed as $\beta$-glucuronidase activity. Reductions in $\beta$-glucuronidase activity of root tissues can be caused by lower populations of Foln3GUS on or in roots, lower $\beta$-glucuronidase activity expressed by individual propagules of Foln3GUS, or a combination of these factors. Both the population size of Foln3GUS and $\beta$-glucuronidase activity were assessed; therefore, these different possibilities could be addressed in the current study.

At the Fo47 to Foln3GUS inoculum ratio of 10:1, Fo47 decreased the $\beta$-glucuronidase activity expressed by Foln3GUS without reducing the density of the pathogen on flax roots. Therefore, disease suppression by Fo47 could be attributed to a decrease in the metabolic activity of Foln3GUS rather than to a decrease in the number of Foln3GUS propagules associated with flax roots. This result is consistent with the observation made by Olivain and Alabouvette (32), showing that only actively growing hyphae of $F$. oxysporum can penetrate the root. Reductions in the carbon metabolism of the pathogen may result in a decreased number of root infections and consequently reduced disease severity. These reductions could reflect a decrease in the carbon sources available for the pathogen resulting from the carbon competition achieved by

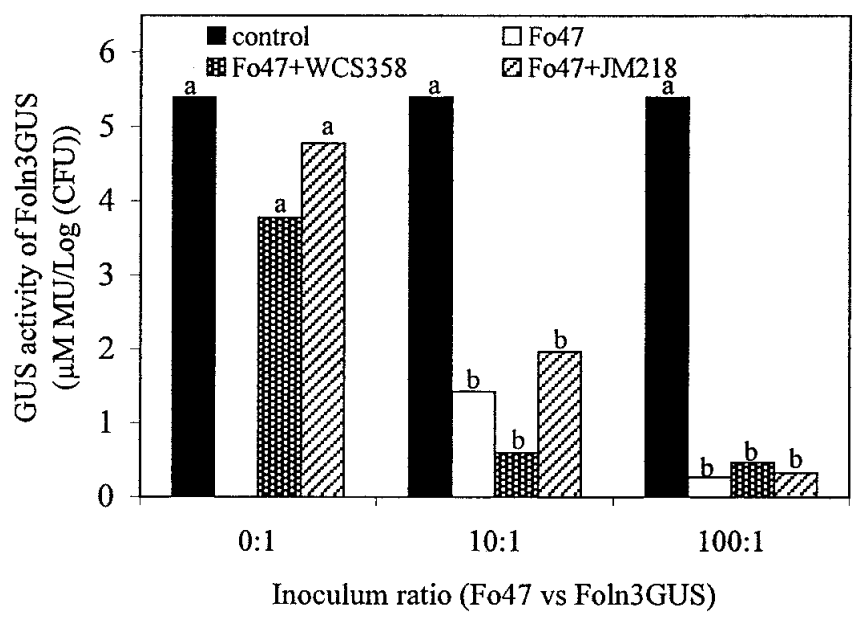

Fig. 4. Comparison of the effects of Pseudomonas putida WCS358 and the $\mathrm{Sid}^{-}$mutant JM218 on the $\beta$-glucuronidase activity of Foln3GUS for different inoculum ratios of nonpathogenic Fusarium oxysporum Fo47 to pathogenic F. oxysporum Foln3GUS. For the same Fo47 to Foln3GUS inoculum ratio, means designated with the same letter are not significantly different $(P \leq 0.05)$ according to Fisher's least significant difference test.
Fo47, as previously demonstrated in vitro (24). This analysis could not be made in the previous work of Eparvier and Alabouvette (12), because Foln3GUS could not be distinguished from Fo47 by the antibody used to evaluate root colonization by the fungi; therefore, populations of Foln3GUS were not enumerated and the metabolic activity could not be normalized to the pathogen density.

At the highest inoculum dose of Fo47 (100:1, Fo47 to Foln3GUS), both the density of the pathogen and the $\beta$-glucuronidase activity were reduced and disease was less severe than that observed at the lower inoculum dose of Fo47 (10:1, Fo47 to Foln3GUS). The increased efficacy of biocontrol with a greater inoculum dose of Fo47 is consistent with a possible role for competition for carbon and infection sites in suppression of Fusarium wilt (7,24,32).

In the presence of $P$. putida WCS358, suppression of Fusarium wilt of flax by nonpathogenic $F$. oxysporum Fo47, when inoculated at a ratio of 10:1 (Fo47 to Foln3GUS), was increased significantly, as previously described on carnation (23). At this inoculum ratio, enhanced disease control by the microbial combination was related to a significant reduction of the pathogen density but not to a reduction of pathogen activity on or in roots. In contrast, the $\mathrm{Sid}^{-}$ mutant JM218 did not further reduce disease severity or the population density of the pathogen beyond that achieved by Fo47 alone. Because the population sizes of JM218 and WCS358 were similar at the root level, the lack of efficacy of the $\mathrm{Sid}^{-}$mutant could not be ascribed to reduced fitness of the strain. The conclusion that in situ pyoverdine production contributes to disease suppression by WCS358 was supported by data indicating that iron availability to the bacterium at the root level, assessed by the ice-nucleation reporter gene, was sufficiently low for pyoverdine production. Together, these results provide convincing evidence that WCS358 suppresses Fusarium wilt of flax by inhibiting the saprophytic growth of the pathogen and that pyoverdine produced in situ by WCS358 contributes to this inhibition. Pyoverdine produced by P. putida WCS358 is known to inhibit mycelial growth of a pathogenic $F$. oxysporum in culture (24), and the current data indicate that this inhibition can also occur at the root level. These results also confirm those from a previous study, indicating that pyoverdine production contributes to the conjoint activities of WCS358 and the nonpathogenic $F$. oxysporum Fo47 for biological control of Fusarium wilt of carnation (23).

In contrast with the Fo47 to Foln3GUS inoculum ratio of 10:1, at inoculum ratio of 100:1, neither WCS358 nor JM218 modified the density or the activity of the pathogen at the root level. They also failed to improve the control achieved by Fo47. The difference in the effect of WCS358 on disease severity according to the Fo47 to Foln3GUS inoculum ratio could be related to the higher

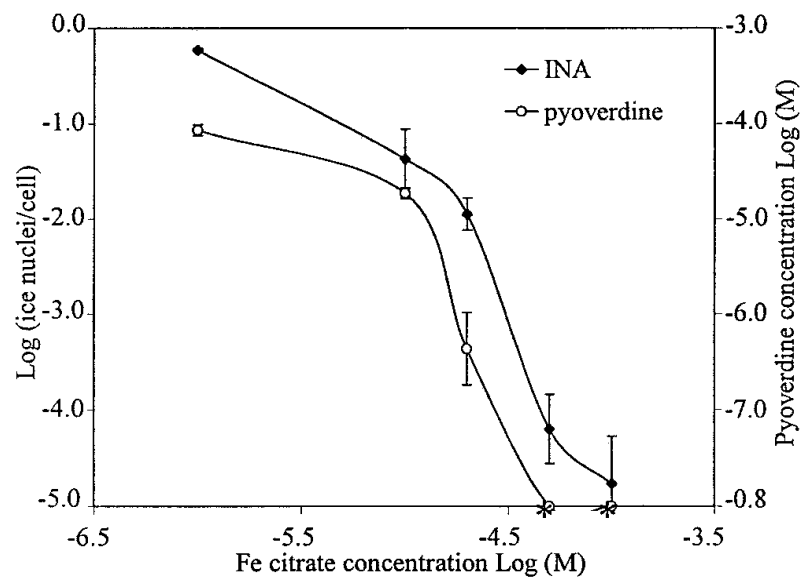

Fig. 5. Relationship between ice-nucleation activity (INA) and pyoverdine production by Pseudomonas putida WCS358pvd-inaZ grown in RSM amended with increasing concentrations of ferric citrate. Vertical bars indicate standard errors and $*$ indicates pyoverdine below the detection limit. 
density of Fo47 at the inoculum ratio 100:1 that would have led to an increased susceptibility of Fo47 to the bacterial antagonism. The $\mathrm{Sid}^{-}$mutant JM218 increased significantly the disease severity when compared with Fo47 alone but nonsignificantly when compared with WCS358 + Fo47. The disease severity in the presence of the microbial combinations, however, remained significantly lower than the infested control.

Besides microbial competition, induction of resistance of the host plant by biocontrol agents is another mode of action that can suppress Fusarium wilt $(22,36)$. Previous studies have demonstrated that nonpathogenic $F$. oxysporum Fo47 and $P$. putida WCS358 can induce systemic resistance of plants against Fusarium wilt $(7,11$, 36). In addition, siderophores and, more specifically, pyoverdines have been shown to play a role in the induction of resistance of the host plant against different diseases $(19,28)$. In this study, systemic induced resistance could not be excluded, because Fo47 reduced disease severity even in the absence of any significant decrease of the pathogen density (at an inoculum ratio of 10:1 [Fo47 to Foln3GUS]). However, disease suppression was more efficient when the pathogen density was decreased significantly by Fo47 at the highest inoculum ratio and by the combination of Fo47 and WCS358 at an inoculum ratio of 10:1 (Fo47 to Foln3GUS). This observation is in agreement with previous work, indicating that systemic induced resistance does not play a major role in the $\mathrm{Fu}$ sarium wilt suppression achieved by Fo47 (11). The implication of the antagonism in the disease suppression by the microbial combination is also supported by the fact that $P$. putida WCS358 improved the biocontrol activity of Fo47 only when the bacterial strain enhanced the reduction of the pathogen density achieved by Fo47 alone (ratio 10:1). According to our previous work (24), the strong antagonism associated with the combination of Fo47 and WCS358 at the inoculum ratio 10:1 could be related to an interaction between the competition for carbon and iron performed by Fo47 and WCS358, respectively.

In conclusion, the current study provides evidence that suppression of Fusarium wilt of flax by a $P$. putida and a nonpathogenic $F$. oxysporum is related to a reduction of the pathogen density and activity on roots, and the antagonism achieved by $P$. putida WCS358 is related to pyoverdine production.

\section{ACKNOWLEDGMENTS}

Dedicated to the memory of Ben Duijff. This work was partly supported by the Conseil Régional de Bourgogne (grant to B. J. Duijff, contract number 1312/461). We thank T. Corberand and N. Gautheron for technical assistance, and M. Henkels and B. Nowak-Thompson for their contributions to studies relating ice-nucleation activity to pyoverdine production by WCS358pvd-inaZ in culture.

\section{LITERATURE CITED}

1. Abdallah, M. A. 1991. Pyoverdins and pseudobactins. Pages 139-153 in: Handbook of Microbial Iron Chelates. G. Winkelmann, ed. CRC Press, Inc., Boca Raton, FL.

2. Alabouvette, C., De La Broise, D., Lemanceau, P., Couteaudier, Y., and Louvet, J. 1987. Utilisation de souches non pathogènes de Fusarium pour lutter contre les fusarioses: Situation actuelle dans la pratique. EPPO (Eur. Mediterr.Plant Prot. Organ.) Bull. 17:665-674.

3. Alabouvette, C., and Lemanceau, P. 1998. Joint action of microbials for disease control. Pages 117-135 in: Methods in Biotechnology, Vol. 5: Biopesticides: Use and Delivery. F. R. Hall and J. J. Menn, eds. Humana Press, Inc., Totowa, NJ.

4. Alabouvette, C., Lemanceau, P., and Steinberg, C. 1993. Recent advances in the biological control of Fusarium wilts. Pestic. Sci. 37:365-373.

5. Bakker, P. A. H. M., Lamers, J. G., Bakker, A. W., Marugg, J. D., Weisbeek, P. J., and Schippers, B. 1986. The role of siderophores in potato tubers yield increase by Pseudomonas putida in a short rotation of potato. Neth. J. Plant Pathol. 92:249-256.

6. Buyer, J., Sikora, L. J., and Chaney, R. 1989. A new growth medium for the study of siderophore-mediated interactions. Biol. Fertil. Soils 8:98-101.

7. Couteaudier, Y., and Alabouvette, C. 1990. Quantitative comparison of Fusarium oxysporum competitiveness in relation to carbon utilization. FEMS
(Fed. Eur. Microbiol. Soc.) Microbiol. Ecol. 74:261-268.

8. Couteaudier, Y., Daboussi, M. J., Eparvier, A., Langin, T., and Orcival, J. 1993. The GUS gene fusion system (Escherichia coli $\beta$-D-glucuronidase gene), a useful tool in studies of root colonization by Fusarium oxysporum. Appl. Environ. Microbiol. 59:1767-1773.

9. Duijff, B. J., Bakker, P. A. H. M., and Schippers, B. 1994. Suppression of Fusarium wilt of carnation by Pseudomonas putida WCS358 at different levels of disease incidence and iron availability. Biocontrol Sci. Technol. 4:279-288.

10. Duijff, B. J., Meijer, J. W., Bakker, P. A. H. M., and Schippers, B. 1993. Siderophore-mediated competition for iron and induced resistance in the suppression of Fusarium wilt of carnation by fluorescent Pseudomonas spp. Neth. J. Plant Pathol. 99:277-289.

11. Duijff, B. J., Pouhair, D., Olivain, C., Alabouvette, C., and Lemanceau, P. 1998. Implication of systemic induced resistance in the suppression of Fusarium wilt of tomato by Pseudomonas fluorescens WCS417r and nonpathogenic Fusarium oxysporum Fo47. Eur. J. Plant Pathol. 104:903910.

12. Eparvier, A., and Alabouvette, C. 1994. Use of ELISA and GUS-transformed strains to study competition between pathogenic and non-pathogenic Fusarium oxysporum for root colonization. Biocontrol Sci. Technol. 4:35-47.

13. Fuchs, J. G., Moënne-Loccoz, Y., and Défago, G. 1997. Nonpathogenic Fusarium oxysporum Fo47 induces resistance to Fusarium wilt in tomato. Plant Dis. 81:492-496.

14. Geels, F. P., and Schippers, B. 1983. Selection of antagonistic fluorescent Pseudomonas spp. and their root colonization and persistence following treatment of seed potatoes. Phytopathol. Z. 108:193-206.

15. Itoh, Y., Watson, J. M., Haas, D., and Leisinger, T. 1984. Genetic and molecular characterization of the Pseudomonas plasmid pVS1. Plasmid 11:206-220.

16. King, E. O., Ward, M. K., and Raney, D. E. 1954. Two simple media for the demonstration of pyocyanin and fluorescin. J. Lab. Clin. Med. 44: 301-307.

17. Kloepper, J. W., Leong, J., Teintze, M., and Schroth, M. N. 1980. Pseudomonas siderophore: A mechanism explaining disease suppressive soils. Curr. Microbiol. 4:317-320.

18. Komada, H. 1975. Development of a selective medium for quantitative isolation of Fusarium oxysporum from natural soils. Rev. Plant Prot. Res. 8:114-125.

19. Leeman, M., Den Ouden, F. M., Van Pelt, J. A., Cornelissen, C., Bakker, P. A. H. M., and Schippers, B. 1996. Suppression of Fusarium wilt of radish by co-inoculation of fluorescent Pseudomonas spp. and root colonizing fungi. Eur. J. Plant Pathol. 102:21-31.

20. Lemanceau, P. 1989. Role of competition for carbon and iron in mechanisms of soil suppressiveness to Fusarium wilts. Pages 386-396 in: Vascular Wilt Diseases of Plants, Basic Studies and Control. E. C. Tjamos and C. H. Beckman, eds. Springer Verlag, Berlin.

21. Lemanceau, P., and Alabouvette, C. 1991. Biological control of Fusarium diseases by fluorescent Pseudomonas and non-pathogenic Fusarium. Crop Prot. 10:279-286.

22. Lemanceau, P., and Alabouvette, C. 1993. Suppression of Fusarium-wilts by fluorescent pseudomonads: Mechanisms and applications. Biocontrol Sci. Technol. 3:219-234.

23. Lemanceau, P., Bakker, P. A. H. M., De Kogel, W. J., Alabouvette, C., and Schippers, B. 1992. Effect of pseudobactin 358 production by Pseudomonas putida WCS358 on suppression of Fusarium wilt of carnations by nonpathogenic Fusarium oxysporum Fo47. Appl. Environ. Microbiol. 58:2978-2982.

24. Lemanceau, P., Bakker, P. A. H. M., De Kogel, W. J., Alabouvette, C., and Schippers, B. 1993. Antagonistic effect of nonpathogenic Fusarium oxysporum Fo47 and pseudobactin 358 upon pathogenic Fusarium oxysporum f. sp. dianthi. Appl. Environ. Microbiol. 59:74-82.

25. Loper, J. E., and Lindow, S. E. 1994. A biological sensor for iron available to bacteria in their habitats on plant surfaces. Appl. Environ. Microbiol. 60:1934-1941.

26. Loper, J. E., and Lindow, S. E. 1996. Reporter genes useful in evaluating in situ gene expression by soil and plant-associated bacteria. Pages 482492 in: Manual of Environmental Microbiology. C. J. Hurst, G. R. Knudsen, M. J. McInerney, L. D. Stetzenbach, and M. V. Walter, eds. ASM Press, Washington, DC.

27. Marugg, J. D., Van Spanje, M., Hoekstra, W. P. M., Schippers, B., and Weisbeek, J. P. 1985. Isolation and analysis of gene involved in siderophore biosynthesis in plant growth-stimulating Pseudomonas putida WCS358. J. Bacteriol. 164:563-570.

28. Maurhofer, M., Hase, C., Meuwly, P., Métraux, J.-P., and Défago, G. 1994. Induction of systemic resistance of tobacco to tobacco necrosis virus by the root-colonizing Pseudomonas fluorescens strain CHA0: Influence of the gacA gene and pyoverdin production. Phytopathology 84:139-146. 
29. Meyer, J.-M., and Abdallah, M. A. 1978. The fluorescent pigment of Pseudomonas fluorescens: Biosynthesis, purification and physico-chemical properties. J. Gen. Microbiol. 107:319-328.

30. Miller, J. H. 1972. Experiments in Molecular Genetics. Cold Spring Harbor Laboratory, Cold Spring Harbor, NY.

31. Nowak-Thompson, B., and Gould, S. J. 1994. A simple assay for fluorescent siderophores produced by Pseudomonas species and an efficient isolation of pseudobactin. BioMetals 7:20-24.

32. Olivain, C., and Alabouvette, C. 1997. Colonization of tomato roots by a non-pathogenic strain of Fusarium oxysporum. New Phytol. 137: 481-494.

33. Park, C. S., Paulitz, T. C., and Baker, R. 1988. Biocontrol of Fusarium wilt of cucumber resulting from the interactions between Pseudomonas putida and non-pathogenic isolates of Fusarium oxysporum. Phytopathol- ogy 78:190-194.

34. Rouxel, F., Alabouvette, C., and Louvet, J. 1979. Recherches sur la résistance des sols aux maladies. IV. Mise en évidence du rôle des Fusarium autochtones dans la résistance d'un sol à la fusariose vasculaire du melon. Ann. Phytopathol. 11:199-207.

35. Schippers, B. 1992. Prospects for management of natural suppressiveness to control soilborne pathogens. Pages 21-34 in: Biological Control of Plants Diseases: Progress and Challenges for the Future. E. C. Tjamos, G. C. Papavizas, and R. J. Cook, eds. Plenum Press, New York.

36. Van Loon, L. C., Bakker, P. A. H. M., and Pieterse, C. M. J. 1998. Systemic resistance induced by rhizosphere bacteria. Annu. Rev. Phytopathol. 36:453-483.

37. Weller, D. M. 1988. Biological control of soilborne plant pathogens in the rhizosphere with bacteria. Annu. Rev. Phytopathol. 26:379-407. 